\title{
De JGZ-richtlijn Secundaire Preventie Kindermishandeling: een complexe richtlijn landelijk implementeren. Hoe gaat dat?
}

\begin{abstract}
Twee jaar na de lancering van de JGZ-richtlijn Secundaire Preventie Kindermishandeling is gestart met de landelijke implementatie van deze richtlijn. Hierbij zijn JGZ-organisaties door 3 organisaties begeleid bij de implementatie binnen hun organisatie, namelijk: het Nederlands Centrum Jeugdgezondheid (NCJ), het Nederlands Jeugdinstituut (NJi) en TNO Behavioural and Societal Sciences (TNO BSS). Deze organisaties kregen een handleiding en materialen uitgereikt, waarmee ze de implementatie concreet konden vormgeven. Daarnaast kregen zij toegang tot een besloten platform om onderling informatie te delen en van elkaars ervaringen te leren. Aan een landelijke informatiebijeenkomst namen 38 organisaties deel; 13 organisaties meldden zich daarna nog aan voor het Virtueel Samenwerkingsplatform (VSP) dat in verband met de implementatie was opgezet. In totaal waren daarmee 51 organisaties bij de implementatie betrokken. Hiervan hebben er 42 deelgenomen aan het evaluatieonderzoek. Uit dit onderzoek bleek dat JGZ-organisaties heel gemotiveerd aan de slag zijn gegaan en in korte tijd veel implementatieactiviteiten hebben uitgevoerd. De belangrijkste activiteiten betroffen het aanstellen van een implementatiecoördinator, het opstellen van een implementatiediagnose, het schrijven van een implementatieplan (inclusief scholingsplan) en het organiseren van een interne startbijeenkomst voor medewerkers. De evaluatie van dit landelijke traject heeft veel inzicht gegeven in de organisatie en effecten van landelijke begeleiding van de implementatie van JGZrichtlijnen en heeft belangrijke lessen opgeleverd voor toekomstige JGZ-richtlijnen.
\end{abstract}

\section{Inleiding}

In 2009 is de JGZ-richtlijn Secundaire Preventie Kindermishandeling gepubliceerd. ${ }^{1}$ Hoewel het JGZ-veld goed doordrongen is van het belang van het werken volgens richtlijnen, heeft het implementeren van een richtlijn in de jeugdgezondheidszorg doorgaans meer voeten in de aarde dan wordt gedacht. Implementatie vereist allereerst een grote motivatie van managers en medewerkers. Daarnaast vraagt implementatie een flinke tijdsinvestering. Ook is het van belang dat medewerkers over de juiste kennis en materialen beschikken. Daarom werd de implementatie van deze richtlijn in opdracht van ZonMw op landelijk niveau vanuit drie organisaties begeleid, namelijk het Nederlands Centrum Jeugdgezondheid (NCJ), het Nederlands Jeugdinstituut (NJi) en TNO Behavioural and Societal Sciences (TNO BSS). Het was de bedoeling om het gebruik van de richtlijn binnen JGZ-organisaties makkelijker van de grond te laten komen.

Reeds in 2008 is de implementatie van de richtlijn voor het eerst uitgetest in vier JGZ-organisaties. Op basis van de lessen uit deze proefimplementatie ${ }^{2-5}$ en met het aansluitend ontwikkelde materiaal ${ }^{6}$ is in maart 2011 de landelijke implementatie van start gegaan. Een groot aantal JGZ-organisaties heeft deelgenomen aan een landelijk traject waarin in begeleiding werd voorzien bij de implementatie van de richtlijn binnen hun eigen organisatie. Uit de evaluatie van de implementatieactiviteiten bleek dat de JGZ-organisaties gemotiveerd en enthousiast aan de slag zijn gegaan. Ondanks de vaak krappe budgetten hebben zij in korte tijd belangrijke stappen gezet in het implementatieproces. Dit landelijke traject heeft interessante lessen opgeleverd voor alle navolgende landelijke implementaties van JGZ-richtlijnen.

In dit artikel zullen we stilstaan bij de manier waarop de landelijke implementatie is ondersteund en uitgevoerd. We geven een beknopt overzicht van wat organisaties hebben bereikt en tot slot wordt stilgestaan bij de leerpunten voor toekomstige implementaties.

\section{Doelstellingen}

Voor het implementatietraject met een totale looptijd van 14 maanden werden de volgende 3 einddoelen gesteld:

\footnotetext{
A. Broerse, onderzoeker, en M. Kamphuis, senior onderzoeker en jeugdarts KNMG, TNO Behavioural and Societal Sciences, Leiden. K. Kooijman, senior medewerker, en M. Vergeer, senior onderzoeker en trainer, Nederlands Jeugdinstituut, Utrecht. M. Beckers, senior adviseur, Nederlands Centrum Jeugdgezondheid, Utrecht. Correspondentieadres: TNO Behavioural and Societal Sciences, Wassenaarseweg 56, Postbus 2215, 2301 CE Leiden, annelies.broerse@tno.nl.
} 
1. Binnen JGZ-organisaties zijn een implementatiecoördinator en aandachtsfunctionaris aangesteld.

2. JGZ-organisaties hebben een implementatieplan en scholingsplan geschreven.

3. JGZ-organisaties hebben de richtlijn verankerd en werken ermee (al dan niet via verwerking in het eigen organisatieprotocol).

\section{Methoden}

Het landelijke implementatietraject zag er in chronologische volgorde als volgt uit:

1. Informatiebijeenkomst. In maart 2011 werden voor alle $58 \mathrm{JGZ}$-organisaties in Nederland op 2 locaties informatiebijeenkomsten georganiseerd, bedoeld voor aandachtsfunctionarissen kindermishandeling en implementatiecoördinatoren. Dit betrof een instructie van een hele dag, waarbij de sleutelfiguren kennis, instrumenten, een werkwijze en een ondersteuningstraject kregen aangeboden, om de implementatie van de richtlijn binnen de eigen organisatie te begeleiden. ${ }^{6}$

2. Implementatiediagnose, implementatieplan (inclusief scholingsplan) en interne startbijeenkomst. De sleutelfiguren hebben tijdens de informatiebijeenkomst de stand van zaken in hun eigen organisatie geïnventariseerd (implementatiediagnose) en vastgesteld waar behoefte aan was. Op basis hiervan is vervolgens een implementatieplan geschreven. Voor het scholingsplan maakten JGZ-organisaties zelf een keuze in onderwerpen en aanbieders. Hierbij kon gebruik gemaakt worden van het landelijk overzicht van scholingsaanbieders van het NJi (www.nji.nl > databank na- en bijscholing kindermishandeling en de website Landelijke Training Aanpak Kindermishandeling: www.ltak. $\mathrm{nl})$.

3. Begeleiding en onderlinge kennisuitwisseling tussen JGZ-organisaties. Bij het opstellen van de implementatiediagnose en het implementatieplan (en scholingsplan) en het uitvoeren van de interne startbijeenkomst boden NJi en TNO zo nodig begeleiding in de vorm van advies en consultatie. Daarnaast werd door het NJi een virtueel samenwerkingsplatform (VSP) ontwikkeld. Dit is een projectsite waarvoor de sleutelfiguren een inlogcode kregen. Hierop konden sleutelfiguren tijdens het traject onderling informatie uitwisselen. Het VSP was bedoeld om de kennisopbouw en onderlinge uitwisseling onder aandachtsfunctionarissen en/of implementatiecoördinatoren te stimuleren.

4. Evaluatieonderzoek en good practices. Op twee ijkmomenten ( 6 en 12 maanden na de informatiebijeenkomsten) verzamelde TNO met digitale vragenlijsten informatie over de voortgang van de implementatieactiviteiten binnen JGZ-organisaties. De vragenlijsten werden toegestuurd aan iedereen die aanwezig was bij de landelijke informatiebijeenkomsten en aan een aantal personen die zich later nog via het VSP aanmelden. Dit betrof veelal aandachtsfunctionarissen kinder- mishandeling of implementatiecoördinatoren. Zij traden hierbij op als vertegenwoordigers van hun organisatie. In de vragenlijsten werden onder andere vragen gesteld over: 1) het aanstellen van een implementatiecoördinator en aandachtsfunctionaris, 2) het opstellen van een implementatieplan en scholingsplan, 3) de uitvoering van enkele andere essentiële implementatieactiviteiten, zoals het uitvoeren van een implementatiediagnose en het organiseren van een interne startbijeenkomst voor medewerkers, 4) het gebruik van het VSP en 5) de kwaliteit van landelijke begeleiding. Daarnaast werd ook gevraagd naar borging van de implementatie in de eigen organisatie en welke implementatieactiviteiten men in de komende tijd nog zou opstarten. Tot slot werd gevraagd naar de implementatieactiviteit waarover men het meest tevreden was. Het antwoord op deze vraag vormde de basis voor het selecteren van good practices, bedoeld om JGZ-organisaties wederzijds van elkaars kennis en ervaring te laten profiteren. Het criterium voor het bepalen of iets wel of geen good practice was, was naast de tevredenheid van de JGZ-organisatie zelf, de inschatting van de onderzoekers van het belang van de good practice voor andere organisaties, ofwel de inspiratiewaarde.

\section{Resultaten}

In totaal waren bij de informatiebijeenkomsten 55 personen aanwezig. Zij vertegenwoordigden 38 van de in totaal 58 Nederlandse JGZ-organisaties (66\%). Deze 55 deelnemers kregen in april een persoonlijke inlogcode en een handleiding toegestuurd voor het VSP. In de maanden daarna hebben zich nog 36 andere geïnteresseerden uit 13 nog niet deelnemende organisaties aangemeld. Zij konden de implementatiehandleiding en documenten van het VSP downloaden. Hiermee kwam het totaal aantal betrokken organisaties bij de landelijke implementatie op 51.

In het kader van het evaluatieonderzoek werden de eerste en tweede vragenlijst toegestuurd aan respectievelijk 78 en 77 personen uit 51 verschillende JGZ-organisaties. De vragenlijsten werden door de aandachtsfunctionarissen en/of implementatiecoördinatoren respectievelijk voor 41 (80\%) en 33 (65\%) van de JGZ-organisaties ingevuld. In totaal werd op deze manier uit $42 \mathrm{JGZ}$-organisaties informatie verkregen over de uitgevoerde implementatieactiviteiten (naast de 41 organisaties die aan het eerste vragenlijstonderzoek meededen, deed namelijk 1 nieuwe organisatie mee aan het tweede vragenlijstonderzoek).

Uit de evaluatie bleek allereerst dat in alle 42 JGZ-organisaties een aandachtsfunctionaris was aangesteld en dat in $52 \%$ van de organisaties een implementatiecoördinator was aangewezen. In $55 \%$ van de organisaties was een implementatiediagnose opgesteld en in $64 \%$ van de organisaties was een implementatieplan gemaakt. Iets 
vaker was een scholingsplan ontwikkeld, namelijk in $76 \%$ van de organisaties, en in $69 \%$ van de organisaties was een interne startbijeenkomst gehouden. Een deel van de implementatiewerkzaamheden was al eerder op eigen initiatief - uitgevoerd. De implementatiediagnose was in $29 \%$ en het implementatieplan in $19 \%$ van de organisaties al eerder opgesteld. Het scholingsplan was in $31 \%$ van de organisaties al gemaakt en de interne startbijeenkomst was bij $17 \%$ van de organisaties al gehouden voorafgaand aan het 14 maanden-traject. Het evaluatieonderzoek liet verder zien dat er relatief weinig gebruik werd gemaakt van het VSP. Over de hele periode van 14 maanden waren er in totaal 4806 paginabezoekers, met een gemiddelde van 10 bezoekers per dag. Bij aanvang werden door TNO en het NJi verschillende documenten op het platform gezet. Hieraan werden gaandeweg door de deelnemers slechts enkele documenten toegevoegd. Er is gedurende het traject op verschillende manieren geprobeerd om de activiteit op het platform te stimuleren (via persoonlijke aanmoedigingse-mails en het expliciet stellen van vragen op het forum). Uit het evaluatieonderzoek bleek dat de helft van de deelnemers geen mening had over het VSP, omdat ze er niet of nauwelijks gebruik van hadden weten te maken (veelal vanwege tijdgebrek). Een kwart van de deelnemers was positief en een kwart had aanmerkingen op het gebruiksgemak of de inhoud.

Uit de antwoorden van JGZ-organisaties op de vraag over welke implementatieactiviteit ze het meest tevreden waren, werd een eerste selectie gemaakt van 15 mogelijke good practices. Om deze good practices beter in beeld te krijgen, werden 15 respondenten (uit 15 verschillende organisaties) per e-mail uitgenodigd om een nadere toelichting te geven. Alle 15 respondenten hebben gereageerd en aanvullende documenten toegestuurd. Hieruit bleek dat sommige organisaties meerdere good practices hadden. Daarom is in een tweede selectieronde met 9 respondenten contact gezocht voor nadere uitdieping van in totaal 13 good practices. Deze zijn in een rapportage beschreven die is te downloaden via de websites van TNO, NJi en het NCJ (www.tno.nl > thema's > gezond leven $>$ projecten $>$ jgz-richtlijnen $>$ downloads; www.nji. $\mathrm{nl}>$ Publicaties > Kindermishandeling; www.ncj.nl). ${ }^{7}$

In de tweede vragenlijst is aan de respondenten gevraagd of er activiteiten waren ondernomen om de implementatie van de richtlijn te verankeren. Acht respondenten gaven aan dat dit niet het geval was en 33 respondenten gaven aan dat dit inderdaad gedaan was. Slechts de helft van de respondenten vond de verankering geslaagd. In deze tweede vragenlijst werd eveneens gevraagd wat men van de landelijke begeleiding door het NJi, NCJ en TNO vond. Eenendertig respondenten vonden de begeleiding voldoende tot goed. Als toelichting werd vaak gegeven dat men de informatiebijeenkomst en materialen zeer had gewaardeerd.
Good practices

1. GGD Amsterdam: voldoende uren implementatiecoordinator.

2. GGD Amsterdam schept duidelijkheid in Meldcode versus JGZ-richtlijn Kindermishandeling.

3. GGD Hart voor Brabant brengt de aandachtsfunctionarissen over het voetlicht.

4. GGD Hollands Midden gaat voor scholing op maat.

5. De Zorgboog stelt efficiënt haar implementatiediagnose op.

6. Het digitale handelingsprotocol: acht JGZ-organisaties doen mee.

7. GGD Midden Nederland maakt een overzichtelijk implementatieplan.

8. GGD Midden Nederland creëert draagvlak bij management.

9. GGD Rivierenland en Stichting Thuishulp en Maatschappelijk werk Rivierenland (STMR) maken één protocol voor de JGZ-richtlijn, verwijsindex, standpunt preventie vrouwelijke genitale verminking (VGV) en meldcode.

10. GGD Rivierenland stimuleert de registratie van gegevens door JGZ-medewerkers.

11. GGD Gelderland-Midden steekt in op scholing die aansluit bij CJG en RAAK.

12. Bedrijfscoöperatie integrale Jeugdgezondheidszorg West-Brabant maakt met vier organisaties één plan.

13. GGD Fryslan JGZ integreert JGZ-richtlijn en drie meldcodes.

\section{Discussie en besluiten}

In dit landelijk traject zijn veel lessen geleerd die alle volgende landelijke implementatietrajecten ten goede komen:

Hard gewerkt en veel bereikt. JGZ-organisaties hebben in de periode van maart 2011 tot februari 2012 hard gewerkt aan de implementatie van de JGZ-richtlijn Secundaire Preventie Kindermishandeling. Hoewel de richtlijn al anderhalf jaar eerder beschikbaar was, was de animo voor het landelijk traject groot. Mede door deze grote animo heeft op dit moment het merendeel van alle 58 Nederlandse JGZ-organisaties een groot deel van de belangrijkste onderdelen van het implementatieproces uitgevoerd. Dat is een mooie prestatie, vooral vanwege de krappe budgetten die JGZ-organisaties hiervoor ter beschikking staan. De doelstellingen die aan het begin van het landelijk traject waren gesteld door het NCJ, NJi en TNO zijn ruimschoots behaald. Door het merendeel van de deelnemende JGZ-organisaties is zowel een implementatiecoördinator als een aandachtsfunctionaris aangesteld. Ook is door het merendeel van de JGZorganisaties een implementatieplan en een scholingsplan geschreven. Met name het aanstellen van een aandachtsfunctionaris, het opstellen van een scholingsplan en het organiseren van een interne startbijeen- 
komst kregen binnen JGZ-organisaties relatief veel aandacht (daar werd het vaakst mee gestart). Niettemin zijn het opstellen van een implementatiediagnose en het schrijven van een algemeen implementatieplan onontbeerlijk om een goed overzicht te behouden van alles wat er binnen de organisatie moet gebeuren. Op deze twee punten kan in toekomstige implementatietrajecten dus nog meer nadruk worden gelegd. Het is aan de andere kant hoopvol dat de organisaties die nog een aantal implementatieactiviteiten moeten uitvoeren, aangaven dat ze daarmee in de nabije toekomst zullen starten. Een belangrijke volgende stap voor JGZ-organisaties is het verankeren van de richtlijn. Dit is iets, zo bleek uit het evaluatieonderzoek, wat in veel organisaties nog (verdere) aandacht behoeft. Echter, desgevraagd liet men weten hier veelal al concrete ideeën en plannen voor te hebben.

Reden voor niet-deelname. Naar de redenen voor nietdeelname aan het landelijke traject is geen nader onderzoek gedaan. De indruk bestaat echter, op basis van contacten van de drie begeleidende organisaties met het veld, dat een aantal JGZ-organisaties mogelijk al dusdanig ver gevorderd was met de implementatie, dat een landelijk traject weinig toegevoegde waarde had. Aan de andere kant is het juist ook denkbaar dat een aantal JGZ-organisaties op voorhand al wist dat de implementatie voor hen op dit moment geen prioriteit kon krijgen (bijvoorbeeld vanwege fusies, invoering van het digitaal dossier, etc.).

Landelijke begeleiding heeft meerwaarde. Uit de resultaten van het evaluatieonderzoek kan geconcludeerd worden dat JGZ-organisaties het bij complexe richtlijnen als de JGZ-richtlijn Secundaire Preventie Kindermishandeling prettig vinden om ondersteund te worden. Uit de waardering voor de informatiebijeenkomst en de materialen die daarbij werden uitgereikt, blijkt dat deze vorm van ondersteuning JGZ-organisaties helpt bij de belangrijkste eerste stappen om een complexe JGZ-richtlijn te implementeren. Het is ook bemoedigend dat JGZ-organisaties zich terdege lijken te realiseren dat implementeren meer omvat dan alleen de richtlijn verspreiden of medewerkers scholing aanbieden. Het nut van bijvoorbeeld het opstellen van een implementatiediagnose of het houden van een interne startbijeenkomst werd breed onderschreven.

Uitwisseling tussen JGZ-organisaties is niet vanzelfsprekend. De activiteiten op het besloten VSP dat opgericht was om aandachtsfunctionarissen op een laagdrempelige manier informatie te laten uitwisselen, zijn geëvalueerd. De resultaten lieten zien dat er weinig gebruik werd gemaakt van het VSP. Hoewel het enthousiasme voor deze nieuwe manier van communiceren aanvankelijk groot leek, waren er kennelijk toch te veel factoren die een hoge drempel opwierpen om het platform daadwerkelijk te gaan gebruiken. Er zijn momenteel ook veel digitale vindplaatsen voor informatie over de werkwijze bij kindermishandeling. Het uitwisselen van informatie via een besloten platform zal mogelijk kansrijker zijn als er één platform komt waarop alle informatie rond kindermishandeling wordt gebundeld. Daarnaast is het waardevol om een apart platform op te richten als ontmoetingsplaats voor implementatiecoördinatoren in het algemeen, dus niet alleen voor de richtlijn kindermishandeling. Het NCJ initieert momenteel een netwerk voor implementatiecoördinatoren die zich bezighouden met de implementatie van verschillende JGZ-richtlijnen. Zij kunnen via een digitaal loket implementatietools krijgen en onderling informatie en ervaringen uitwisselen. Dit initiatief is kansrijk omdat deze personen elkaar voor langere periode frequent digitaal, maar ook fysiek zullen treffen. De ervaring leert dat het voor veel mensen laagdrempeliger is om via een platform te communiceren als men de ander ook fysiek heeft ontmoet.

Blijven evalueren. Voor de toekomst geldt dat het belangrijk is voor JGZ-organisaties om de eigen activiteiten te blijven evalueren. Doordat zij hun implementatiedoelstellingen nu expliciet hebben gemaakt in een implementatieplan, is het ook mogelijk om deze doelstellingen te evalueren. Doelstellingen kunnen worden bijgesteld en nieuwe doelen geformuleerd. Hiermee is de kwaliteitscyclus (plan-do-check-act) rond en zullen JGZorganisaties de eigen werkwijze steeds opnieuw naar een hoger plan kunnen trekken. Bovendien zal evaluatie de organisaties inzicht geven in de eigen prestaties met betrekking tot hun werkwijze rond kindermishandeling, wat de positie van JGZ-organisaties in hun dialoog met de gemeenten zal versterken.

Daarnaast is het vanuit landelijk perspectief goed om te blijven monitoren in hoeverre het onderwerp kindermishandeling binnen JGZ-organisaties op de kaart blijft staan. De Inspectie houdt dit in de gaten, maar het NCJ wil daarnaast ook het gebruik van richtlijnen in de praktijk monitoren. Hiermee kan worden nagegaan of alle energie die is gestopt in het ontwikkelen van richtlijnen en de landelijke implementatie daarvan, ook op langere termijn beklijft. Op deze manier kan men permanente verbetering van de richtlijncyclus realiseren.

\section{Dankwoord}

Wij willen alle JGZ-organisaties die deelnamen aan het landelijk traject en het evaluatieonderzoek heel hartelijk danken voor hun inzet en enthousiasme. Hierbij willen wij expliciet de JGZ-organisaties bedanken die hun medewerking verleenden aan het beschrijven van good practices. Wij denken dat zij hiermee de rest van het veld een waardevolle dienst hebben bewezen.

Het onderzoek is uitgevoerd met subsidie van ZONmW. 


\section{Literatuur}

1. Wagenaar-Fischer MM, Heerdink-Obenhuijsen N, Kamphuis M, Wilde J de. JGZ Richtlijn Secundaire Preventie Kindermishandeling. Herziene versie. Leiden: TNO Kwaliteit van Leven; 2009 .

2. Broerse A, Fleuren $M$, Kamphuis $M$, Dommelen P van. Effectonderzoek proefimplementatie JGZ Richtlijn Secundaire Preventie Kindermishandeling. Leiden: TNO Kwaliteit van Leven; 2009.

3. Vergeer M, Geurts E. Handleiding scholing JGZ Richtlijn Secundaire Preventie Kindermishandeling. Utrecht: Nederlands Jeugdinstituut; 2009

4. Vergeer M, Geurts E, Kooijman K. Handleiding implementatie JGZ Richtlijn Secundaire Preventie Kindermishandeling. Utrecht: Nederlands Jeugdinstituut, 2009.

5. Vergeer M, Kooijman K, Geurts E. Aanbevelingen voor landelijke implementatie van de JGZ-richtlijn Secundaire Preventie Kindermishandeling. Utrecht: Nederlands Jeugdinstituut; 2009.

6. Vergeer M, Kooijman K. Handleiding en Bijlagen Landelijke Implementatie JGZ Richtlijn Secundaire preventie kindermishandeling. Utrecht: Nederlands Jeugdinstituut. In samenwerking met het Nederlands Centrum Jeugdgezondheid en TNO Behavioral and Societal Sciences. Maart 2011.

7. Broerse A, Kamphuis M, Kooijman K, Vergeer M, Beckers M. Landelijke implementatie JGZ Richtlijn Secundaire Preventie Kindermishandeling. Evaluatie en good practices. Leiden: TNO Behavioural and Societal Sciences; 2012.

\section{Geef ambitie de ruimte}

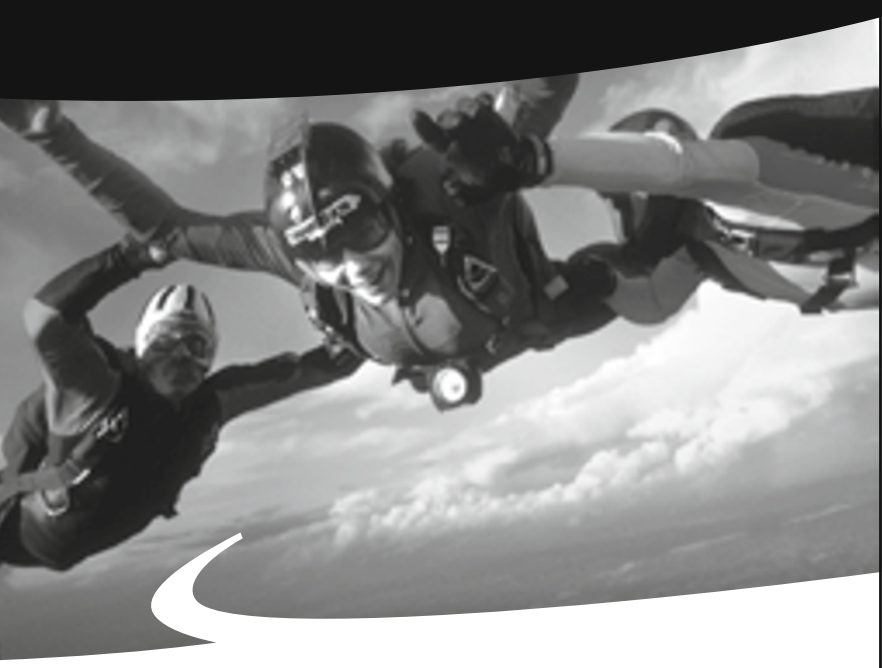

Bent u die ambitieuze, gedreven verpleegkundige die kennis over het vak wil verbreden en verdiepen?

U wilt effectief samenwerken met ketenpartners, problemen in de gezondheid van cliënten signaleren en daarop kunnen acteren?

$U$ wilt een actieve rol spelen in de onderbouwing en vernieuwing van de sociale verpleegkunde?

Kies dan voor de

\section{Opleiding}

\section{Sociaal Verpleegkundige JGZ of AGZ bij de NSPOH}

Een greep uit het programma:

- Organisatie van de publieke gezondheidszorg en actuele ontwikkelingen en vernieuwingen in de AGZ en JGZ

- Gebruik van richtlijnen

- Inhoud AGZ: bijvoorbeeld infectieziektebestrijding, outbreak management, SOA-bestrijding, TBC, hygiënezorg óf

- Inhoud JGZ: lichamelijke en psychosociale ontwikkeling van o-19-jarigen en ondersteuning van gezinnen bij problemen die daarin spelen

- Kansen voor preventie van aandoeningen en het gebruik daarin van sociale media

- Motivational interviewing, pedagogisch adviseren, strategisch samenwerken met ketenpartners.

\section{Interesse?}

Kijk op www.nspoh.nl of neem contact op met Manon Penris van de NSPOH.

Telefoon 020 - 4097021.

E-mailm.penris@nspoh.nl

\section{NSPOH}

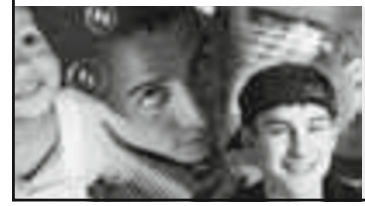

De NSPOH is hét opleidingsinstiturt op het snijvlak van maatschappij, arbeid en gezondheid. Onze onderwijsprogramma's slaan een brug tussen beleid, onderzoek en praktijk. De NSPOH werkt samen met AMC - UvA in de Academische Opleidingswerkplaats AMC/NSPOH. Andere samenwerkingspartners zijn o.a. Erasmus MC, VU MC, UMCG, TNO en RIVM. 